\title{
Offspring of prenatal IV nicotine exposure exhibit increased sensitivity to the reinforcing effects of methamphetamine
}

\author{
Steven B. Harrod *, Ryan T. Lacy and Amanda J. Morgan \\ Behavioral Neuroscience Program, Department of Psychology, University of South Carolina, Columbia, SC, USA
}

\section{Edited by:}

Valentina Echeverria Moran, Bay Pines VA Medical Center, USA

\section{Reviewed by:}

Katie A. Jennings, Oxford University, UK

Boris B. Quednow, University

Hospital of Psychiatry, Switzerland

\section{*Correspondence}

Steven B. Harrod, Behavioral Neuroscience Program, Department of Psychology, University of South Carolina, 1512 Pendleton Street, Columbia, SC 29208, USA.

e-mail: harrods@mailbox.sc.edu
Maternal smoking during pregnancy is associated with increased substance abuse in offspring. Preclinical research shows that in utero exposure to nicotine, the primary psychoactive compound in tobacco smoke, influences the neurodevelopment of reward systems and alters motivated behavior in offspring. The present study determined if prenatal nicotine (PN) exposure altered the sensitivity to the reinforcing and aversive effects of methamphetamine (METH) in offspring using a low dose, intravenous (IV) exposure method. Pregnant dams were administered nicotine $(0.05 \mathrm{mg} / \mathrm{kg} /$ injection) or prenatal saline (PS) $3 \times /$ day on gestational days 8-21, and adult offspring were tested using METH self-administration (experiment 1) or METH-induced conditioned taste aversion (CTA; experiment 2) procedures. For METH self-administration, animals were trained to respond for IV METH $(0.05 \mathrm{mg} / \mathrm{kg} /$ infusion; fixed-ratio 3$)$ and they were tested on varying doses of the reinforcer (0.0005-1.0 mg/kg/infusion). For METH CTA, rats received three saccharin and METH pairings $(0,0.3$, or $0.5 \mathrm{mg} / \mathrm{kg}, \mathrm{sc})$ followed by 14 daily extinction trials. Experiment 1 : PN and PS animals exhibited inverted U-shaped dose-response curves; however, the PN animal's curve was shifted to the left, suggesting PN animals were more sensitive to the reinforcing effects of METH. Experiment 2: METH CTA was acquired in a dose-dependent manner and the factor of PN exposure was not related to the acquisition or extinction of METH-induced CTA. There were no sex differences in either experiment. These results indicate that IV PN-exposed adult offspring exhibited increased sensitivity to IV METH. This suggests that PN exposure, via maternal smoking, will alter the reinforcing effects of METH during later stages of development, and furthermore, will influence substance use vulnerability in adult human offspring.

Keywords: maternal smoking, prenatal nicotine, intravenous, methamphetamine, self-administration, conditioned taste aversion

\section{INTRODUCTION}

Maternal smoking during pregnancy imparts multiple health risks on the fetus (Castles et al., 1999; Ernst et al., 2001; Winzer-Serhan, 2008; Cornelius and Day, 2009). Aside from the well documented effects of maternal smoking to produce low birth weight, restricted intrauterine growth, and increased incidence of sudden infant death syndrome, it is also apparent that offspring are at increased risk of developing substance use disorder. According to clinical research, tobacco smoke-exposed offspring exhibit an increased likelihood of drug abuse if they initiate drug taking behaviors during adolescence (Kandel et al., 1994; Weissman et al., 1999; Brennan et al., 2002; Buka et al., 2003).

Various animal models of prenatal nicotine (PN) exposure have been used to elucidate the influence of nicotine on the neurobehavioral development of offspring (Dwyer et al., 2009; Heath and Picciotto, 2009). In these models, PN is administered to rodents either continuously via osmotic minipump (Slotkin et al., 1987; Levin et al., 1996; Franke et al., 2007), orally, through drinking water (Zhu et al., 1996; Pauly et al., 2004; Paz et al., 2007; Schneider et al., 2010), or through intravenous (IV) injection (LeSage et al., 2006; Harrod et al., 2011; Lacy et al., 2011). Multiple experiments demonstrate that $\mathrm{PN}$ exposure alone produces alterations in the neurodevelopment of the mesocorticolimbic dopamine (DA) system, which in part mediates motivated behavior. Such PN-induced changes are hypothesized to mediate alterations in the behavioral repertoire of adolescent and adult offspring exposed to PN (Pauly et al., 2004; LeSage et al., 2006; Franke et al., 2008; Lacy et al., 2011). For example, experiments using the continuous route of PN exposure resulted in decreased striatal DA content in weanling rats (Richardson and Tizabi, 1994), increased $c$-fos expression in the infralimbic cortex and nucleus accumbens core (Park et al., 2006), and decreased nicotine-evoked DA release in the nucleus accumbens shell of adolescent rats (Kane et al., 2004). In drug self-administration experiments, adolescent offspring exposed to continuous PN acquired cocaine self-administration at a higher unit dose of drug relative to prenatal saline (PS) controls. This finding suggests that PN exposure altered the reinforcing effects of cocaine (Franke et al., 2008). Adult, PN-exposed female offspring 
self-administered a greater number of nicotine infusions than PS rats following a period of forced abstinence, which suggests that $\mathrm{PN}$-exposed offspring exhibited increased motivation to respond for nicotine (Levin et al., 2006). Together, these experiments indicate that continuous PN exposure alters the neurodevelopment of the mesocorticolimbic DA system and that such changes impact the motivation for drug reward.

The present experiments determined if IV PN exposure altered the motivational effects of the highly abused drug methamphetamine (METH) in adult offspring. It is of interest to use the IV route of administration to deliver nicotine because it closely models the nicotine pharmacokinetics of tobacco smoke inhalation (Russell and Feyerabend, 1978; Mactutus, 1989; Booze et al., 1999; Benowitz et al., 2009). The elimination half-life for nicotine $0.05 \mathrm{mg} / \mathrm{kg} /$ injection is approximately $50 \mathrm{~min}$ (Booze et al., 1999), and so this method represents a unique exposure model in that the dam and fetuses experience the bolus delivery of nicotine to the brain followed by a rapid and precipitous clearance (Russell and Feyerabend, 1978; Mactutus, 1989). Moreover, this method may be used to deliver less overall daily amounts of nicotine relative to other exposure models, while still providing a translationally relevant exposure (see Dwyer et al., 2008). IV PN exposure produced changes in brain-derived neurotrophic factor throughout the mesocorticolimbic DA system of adolescent offspring (Harrod et al., 2011). Pre-weanling offspring exhibited hypoactive locomotor activity in response to a novel context (LeSage et al., 2006), and showed deficits in sensorimotor gating of the acoustic startle response (Lacy et al., 2011). Furthermore, adult offspring showed increased motivation for sucrose reward, relative to controls, when rats responded according to a progressive-ratio schedule of reinforcement; and in this study there were no effects of prenatal treatment when fixed-ratio (FR) schedules of reinforcement were used (Lacy et al., 2012). These findings demonstrate that administration of PN via the IV route produces changes in the neurodevelopment of motivational brain systems, and that offspring exhibit behavioral deficits during various stages of neurodevelopment, relative to controls.

The present experiments tested the hypothesis that IV PN exposure will result in offspring that exhibit altered sensitivity to the rewarding and aversive effects of METH using two conditioning procedures: drug self-administration and conditioned taste aversion (CTA). Previous research shows that PN-exposed offspring exhibited altered responding for IV nicotine (Levin et al., 2006) and IV cocaine (Franke et al., 2008), according the drug self-administration procedure. To date, no experiments have determined the effects of PN on the rewarding or aversive effects of $\mathrm{METH}$ in offspring. Investigating METH is of interest because amphetamines alter synaptic monoamine levels in the mesocorticolimbic system differently than other abused drugs, such as nicotine and cocaine. Amphetamines redistribute DA and other monoamines from the presynaptic terminal to the synapse by producing neurotransmitter release from vesicular monoamine transporters; by inhibiting monoamine oxidase, and by reversing DA transporter function (Sulzer et al., 2005). Cocaine and nicotine increase synaptic DA levels by blockade of the DA transporter and nicotinic receptor stimulated DA release, respectively (Laviolette and van der Kooy, 2004; Gether et al., 2006).
Two separate experiments were therefore conducted to determine if $\mathrm{PN}$ offspring exhibit altered appetitive or aversive conditioning to METH during adulthood. In experiment $1, \mathrm{PN}$ animals prenatally exposed to IV nicotine were trained to self-administer METH $(0.05 \mathrm{mg} / \mathrm{kg} /$ infusion $)$ according to a FR schedule of reinforcement. Animals were then tested on multiple doses of IV $\mathrm{METH}$, ranging from 0.0005 to $1.0 \mathrm{mg} / \mathrm{kg} /$ infusion, to assess adult offspring's sensitivity to the reinforcing effects of the drug. Experiment 2 determined if IV PN exposure alters acquisition and/or extinction of METH-induced CTA, the standard method used to assess the aversive effects of an unconditioned stimulus (US). Potential differences in the sensitivity to the aversive effects of METH were of interest because the trajectory for the escalation of drug use may be determined, in part, by the relative response to the aversive and rewarding effects of a drug (Davis and Riley, 2010). This is the first experiment to assess drug-induced CTA in offspring of PN exposure. Adult offspring consumed a saccharin conditional stimulus (CS), which was paired with the METH US $(0,0.3$, or $0.56 \mathrm{mg} / \mathrm{kg}$; sc) to produce CTA learning, and extinction of the conditioned response (CR) was measured, as well.

\section{MATERIALS AND METHODS ANIMALS}

A total of 80 female and 30 male adult, nulliparous SpragueDawley rats were acquired from Harlan Industries, Inc., (Indianapolis, IN, USA). All rats were transported to the animal care facilities in the psychology department at the University of South Carolina and rodent food (ProLab Rat/Mouse/Hamster Chow 3000) and water were provided ad libitum throughout the course of the experiments, except when otherwise specified. All animal cages were provided with Nylabones (Nylabone, Inc.; long lasting durable chew-original; Neptune, NJ, USA) and Nestlets (NestletsT; Ancare, Bellmore, NY, USA), for purposes of environmental enrichment throughout the duration of the study. A Nylabone was replaced if it was thoroughly chewed, and one Nestlet nesting product was placed in the animals' cage when the cage was changed, which occurred $2 \times /$ week. The animal colony was maintained at $21 \pm 2^{\circ} \mathrm{C}, 50 \pm 10 \%$ relative humidity, and a 12L:12D cycle with lights on at 07:00 hours. The protocol for this research methodology was approved by the Institutional Animal Care and Use Committee (IACUC) at the University of South Carolina.

\section{BREEDING}

Following a 7-day habituation period, female rats were housed three per cage, and one male was placed with each triad from approximately 17:00-09:00. Vaginal lavage samples were analyzed daily with a microscope to determine if a sample was spermpositive. When a sample was identified as sperm-positive, the corresponding female was single-caged and that day was considered gestational day (GD) 0 . The weights of the pregnant dams were recorded daily during pregnancy.

\section{SURGERY: INDWELLING, INTERIORIZED JUGULAR CATHETERS}

The internalized jugular catheters used in the present experiment are commercially available from Harlan Industries. The catheterization was performed at Harlan Industries (Indianapolis, IN, 
USA) according the methods of Mactutus et al. (1994) prior to breeding. Briefly, animals were anesthetized with a mixture of ketamine hydrochloride $(100 \mathrm{mg} / \mathrm{kg} / \mathrm{ml})$ and xylazine $(3.3 \mathrm{mg} / \mathrm{kg} / \mathrm{ml})$. Following anesthesia a sterile Intracath IV catheter (Becton, Dickinson and Co., Franklin Lakes, NJ, USA) with a Luer-Lok injection cap (Medex, Inc., Carlsbad, CA, USA) was implanted dorsally in a subcutaneous pouch. The distal end of the catheter was inserted into the left jugular vein, advanced toward the heart, and the catheter was bound with sterile suture. Animals were kept under periodic post-operative observation and returned to the colony upon recovery. On the day following surgery, catheters were flushed with $0.2 \mathrm{ml}$ of heparinized saline.

\section{PN AND PS ADMINISTRATION}

Pregnant dams were randomly assigned to either the PN $(0.05 \mathrm{mg} / \mathrm{kg} / \mathrm{ml})$ or PS groups. Nicotine or saline was administered $3 \times /$ day via internalized IV catheters from GD 8-21. An organism's susceptibility to a teratogen can vary depending on the stage of development (Vorhees, 1986). Implantation occurs on approximately GD 6, and teratogens generally have an all-ornone effect on the organism during the preimplantation phase of development, which is considered to be approximately GD 1-7. GD 8-21 was chosen as the period of IV nicotine administration because this time includes the initial stages of neurogenesis and migration, synaptogenesis, gliogenesis, and myelination. Thus, this period represents a window of prenatal susceptibility for nicotine's teratogenic effects on neural development (Dwyer et al., 2008). Intravenous injections were delivered through the LuerLok injection cap of the subcutaneously implanted injection port. Following the first and second injections catheters were "postflushed" with $0.2 \mathrm{ml}$ of $0.9 \%$ physiological saline because $0.2 \mathrm{ml}$ represents the approximate volume of the catheter. Post-flush of $0.2 \mathrm{ml}$ of heparinized saline was used to flush the catheter and to maintain catheter patency after the third, daily nicotine injection. All IV nicotine, saline, and post-flush injections were $20 \mathrm{~s}$ in duration. All injections were performed during the light portion of the photoperiod, and injections were administered daily at approximately 1000, 1300, and 1600 .

\section{SURROGATE FOSTERING, LITTER COMPOSITION, AND POSTNATAL TESTING}

The day of birth was considered postnatal day (PND) 0. On PND 1 litters were culled to 10 with five males and five females whenever possible. All pups were surrogate-fostered to timed-pregnant, drug naïve dams to prevent poor maternal care (Vorhees, 1986). The developmental milestones of the righting reflex, negative geotaxis, and eye opening was assessed on PND 3-5, 8-10, and 13-17, respectively. For each experiment, only one male and one female randomly selected from each litter were assigned to each treatment group (Holson and Pearce, 1992). The righting reflex was assessed by placing animals on their backs; upon releasing the animals the latency to right themselves to their stomachs was recorded. The righting reflex was assessed in blocks of three trials across three consecutive days with a maximum latency of $25 \mathrm{~s}$ per trial. During negative geotaxis testing animals were placed on a wire mesh grid, positioned in a $25^{\circ}$ downward angle. The latency ( $30 \mathrm{~s}$ maximum) for animals to turn $180^{\circ}$ to face up the slope was recorded.
Negative geotaxis was measured in blocks of three trials across three consecutive days. Each animal's eyes (left and right) were checked for degree of openness across five consecutive days. The degree of openness was rated on a scale of 0-3: $0=$ completely closed; $1=$ any opening exposing the cornea, regardless of how small; $2=$ cornea and pupil are exposed but eye lids are not fully open; 3 = fully open. All animals' weights were recorded on PND $1,7,14$, and 21. Rats were weaned and pair housed, same sex, on PND 21.

\section{EXPERIMENT 1: METH SELF-ADMINISTRATION APPARATUS}

Operant chambers (ENV-008; Med-Associates, St. Albans, VT, USA), housed within sound-attenuating enclosures, were controlled by Med-PC computer interface software. The front and back panels of the chamber were stainless steel and the sides and top were constructed of polycarbonate. The front panel of the chamber allowed access to a recessed food dipper (ENV-202M) through a $5-\mathrm{cm} \times 5-\mathrm{cm}$ opening. Two retractable metal levers (ENV-112BM) on either side of the opening were located $7.3 \mathrm{~cm}$ above a metal grid floor. A dipper equipped with a $0.1-\mathrm{ml}$ cup attached to the end of the dipper arm was raised into the food receptacle, which allowed access to sucrose following the completion of a response requirement. A $28-\mathrm{V}$ white cue light, $3 \mathrm{~cm}$ in diameter, located above each response lever was used to signal time-outs. An infrared sensor (ENV-254-CB) was used to detect head entries into the food receptacle. During drug selfadministration sessions a syringe pump (PHM-100) was used to deliver intravenous infusions through a water-tight swivel (PHM-115).

\section{SUCROSE-MAINTAINED RESPONDING: PRELIMINARY TRAINING}

Prenatal nicotine ( $n=13$ males; $n=9$ females) and PS $(n=9$ males; $n=7$ females) offspring were food restricted in order to maintain $85 \%$ of free-feeding weight for 3 days prior to the beginning of dipper training. Dipper training and autoshaping were conducted according to previous research (Reichel et al., 2008; Lacy et al., 2012). Sucrose (26\% w/v), was used as the reinforcer during initial training sessions. Offspring were between 65 and 75 days of age at the beginning of preliminary training.

\section{SUCROSE-MAINTAINED RESPONDING: FR TRAINING}

Both levers were presented in the chamber, and rats learned to respond for continuous reinforcement during 30-min sessions. A response on the active lever resulted in $4 \mathrm{~s}$ of access to sucrose, whereas responding on the inactive lever was recorded, but not reinforced. After the first day on continuous reinforcement, food was returned to the animal's home cage allowing ad libitum access for the remainder of the experiment. Animals were maintained on the FR-1 schedule for 1 day and then transitioned to a FR-3 for 2 days. Stable responding was operationally defined as greater than 2:1 ratio of active to inactive responses, and a minimum of 50 reinforcements by the second day of FR-3.

\section{SURGERY: INDWELLING, EXTERIORIZED CATHETERS}

Following acquisition of operant responding for sucrose reward animals were allowed to free-feed for a minimum of 5 days before 
undergoing catheterization surgery. Animals were anesthetized with ketamine $(100 \mathrm{mg} / \mathrm{kg} / \mathrm{ml})$ and diazepam $(5 \mathrm{mg} / \mathrm{kg} / \mathrm{ml})$ then implanted with a catheter into the right jugular vein. The catheter exited through a dental acrylic head mount. The head mounts are secured to the skull with metal screws according to the methods of Harrod et al. (2001). Animals were allowed to recover from surgery for a minimum of 6 days during which time their catheters were flushed with heparinized saline $(0.2 \%)$. Animals were weighed daily in order to monitor post-operative recovery.

\section{METH SELF-ADMINISTRATION: FR TRAINING}

During 60-min sessions, both the right and left levers were presented in the operant chamber. For FR-1 training each response on the active lever resulted in a 5.9-s, intravenous infusion of METH $(0.05 \mathrm{mg} / \mathrm{kg} /$ infusion $)$, which delivered approximately $0.1 \mathrm{ml}$ of solution. Responding on the inactive lever was recorded but not reinforced. A 20-s signaled time-out, i.e., the illumination of both cue lights, was initiated with the onset of the syringe pump. Animals were not reinforced for responding on either lever during the signaled time-out. Animals were maintained on the FR-1 schedule for a minimum of 5 days. Once stable responding was exhibited, animals were transitioned to a FR-3 schedule of reinforcement. Stable responding was operationally defined as less than $20 \%$ variability of active lever responding across two consecutive sessions, greater than 2:1 ratio of active to inactive responses, and a minimum of 10 reinforcements per session. Offspring were 95-105 days old when METH self-administration began.

\section{FR TESTING}

After animals had displayed two consecutive days of stable responding on a FR-3 schedule the rats began testing on the same schedule for five different concentrations of METH. The concentrations were $0.0005,0.0025,0.005,0.025$, and $0.1 \mathrm{mg} / \mathrm{kg} /$ infusion, which were presented according to a Latinsquare design. Animals returned to a FR-3 schedule and responded for $0.05 \mathrm{mg} / \mathrm{kg} /$ infusion for a minimum of 1 day between each FR testing session, and these were referred to as maintenance days. All sessions were a maximum of $1 \mathrm{~h}$ in length.

\section{EXPERIMENT 2: METH-INDUCED CTA \\ MATERIALS}

During testing sessions animals received access to water or sucrose via $100 \mathrm{ml}$ graduated cylinders equipped with a \#6.5 rubber stopper and 2.5" straight drinking tube on the home cage (OT-100; Ancare, Bellmore, NY, USA). During the water recovery period standard drinking bottles were used.

\section{PROCEDURE}

\section{Acquisition}

Conditioned taste aversion was assessed using 124 adult animals, 65 males, and 59 females. Offspring were between 92 and 114 days of age at the beginning of the experiment. Two doses of $\mathrm{METH}(0.3$ and $0.56 \mathrm{mg} / \mathrm{kg} / \mathrm{ml})$ were injected subcutaneously (sc) as the US. Control animals were injected with saline (Sal; sc) rather than METH. Animals were assigned to one of the following six groups: PS- 0.3 (male, $n=11$; female, $n=9$ ), PN-0.3 (male, $n=11$; female, $n=11$ ), PS-0.56 (male, $n=11$; female, $n=9$ ), PN0.56 (male, $n=11$; female, $n=11$ ), PS-Sal (male, $n=10$; female, $n=9$ ), PN-Sal (male, $n=11$; female, $n=10$ ). All rats received water restriction for 4 days prior to conditioning. During water restriction rats were given access to water for $15 \mathrm{~min} /$ day in $100 \mathrm{ml}$ graduated cylinders. Conditioning began on day 5 . Animals were presented with the saccharin $(0.1 \% \mathrm{w} / \mathrm{v})$ CS for $30 \mathrm{~min}$, and were then injected with either METH 0.3 or $0.56 \mathrm{mg} / \mathrm{kg}$ as the US or Sal. On day 6, animals were given access to regular drinking water in standard bottles for $30 \mathrm{~min}$, and no injections were administered following water consumption. This procedure was repeated three times in total. Thus, rats were conditioned on days 5, 7, and 9 , and water recovery days occurred on days 6,8 , and 10 . CS-US pairings occurred between 1400 and 1800 . The dependent measure was the amount saccharin consumed on each of the three conditioning days. Saccharin consumption was weight-corrected $[(\mathrm{ml}$ consumed $) /($ body weight in grams $)]$ because of the baseline sex difference in body weight.

\section{Extinction}

Repeated exposure to the CS in the absence of the US will result in a progressive attenuation of the CR. In order to generate extinction curves for the PS and PN rats, all animals were administered a daily, two-bottle test on days 11-24. During two-bottle testing, the bottles contained either water or saccharin, and the bottles were placed on the cage in a balanced manner across groups. Animals were given access to the bottles for $30 \mathrm{~min}$. Preference scores were derived by dividing the amount of saccharin consumed by the combined amount of saccharin and water consumed. The scores derived from this measure range from 0 to 1.0. Scores greater than 0.5 indicate a preference for saccharin, and scores below 0.5 show a preference for water. Males and females from each prenatal treatment and drug treatment were represented during each of the conditioning and testing sessions. Extinction tests occurred between 1400 and 1800 .

\section{DRUGS}

Nicotine hydrogen tartrate and METH hydrochloride were acquired from Sigma-Aldrich Pharmaceuticals (St. Louis, MO, USA). Nicotine (base weight) and METH (salt weight) were dissolved in physiological saline $(0.9 \%$; Hospira, Inc., Lake Forest, IL, USA). The $\mathrm{pH}$ of the nicotine solution was neutralized to approximately 7.0 with $\mathrm{NaOH}$. Heparin (APP Pharmaceuticals, Schaumburg, IL, USA) was added to saline and the heparinized saline solution $(2.5 \%)$ was used to flush the IV catheters.

\section{DATA ANALYSIS}

\section{General: litter parameters}

The between-subjects factors for the litter parameter analyzes were Sex and Prenatal treatment (PN or PS). The within-subjects factors were PND and GD. A one-way analysis of variance (ANOVA) was conducted for the total number of pups born to PN and PS dams. A Sex $\times$ Prenatal Treatment factorial ANOVA was used to analyze the ratio of males to females born to PN and PS dams. A Sex $\times$ Prenatal Treatment $\times$ PND mixed-factorial ANOVA was conducted for the pup weight gain, righting reflex, negative geotaxis, and eye opening data. A Prenatal Treatment $\times$ GD mixed-factorial ANOVA determined if there were differences between PS and PN dams on the measure of maternal weight gain. 


\section{Experiment 1: METH self-administration}

The dependent measure for the METH self-administration study was active lever presses. Analysis of the FR-3 testing data utilized a $2 \times 2 \times 5$ mixed-factorial ANOVA. The between-subjects factors were Prenatal Treatment and Sex, and the within-subjects factor was Dose (METH dose; 0.0005, 0.0025, 0.005, 0.025, $0.1 \mathrm{mg} / \mathrm{kg} /$ infusion). The same factorial ANOVA was also conducted on the inactive lever data. These analyses were considered significant at $p<0.05$.

\section{Experiment 2: METH-induced CTA}

The acquisition data were analyzed with a $2 \times 2 \times 3 \times 3$ mixedfactorial ANOVA. The between-subjects factors were Prenatal Treatment, Sex, and Dose (0, 0.3, $0.56 \mathrm{mg} / \mathrm{kg} \mathrm{METH})$. The withinsubjects factor was Day, which represents the 3-days of conditioning trials. The dependent measure for the acquisition data was saccharin consumption $(\mathrm{ml} / \mathrm{g})$. Because there was a significant main effect of sex on the weight-corrected data, which indicates that females consumed more saccharin relative to males, the percent of control data were analyzed with a $2 \times 2 \times 3 \times 2$ mixed-factorial ANOVA (the factor of dose was reduced to two) in order to account for the baseline sex difference in saccharin consumption.

A $2 \times 2 \times 3 \times 14$ mixed-factorial ANOVA was used to analyze the two-bottle, extinction data. The between-subjects factors were Prenatal Treatment, Sex, and Dose. The within-subjects factor was Day. For the extinction data, the dependent measure was saccharin preference score [(saccharin) $/($ saccharin + water $)]$. Following a significant Dose $\times$ Day interaction, dependent $t$-tests were conducted on days 1 and 14 of extinction to confirm if animals in the SAL, METH 0.3, and METH 0.56 groups exhibited a change in preference, i.e., extinction, from day 1 to day 14. Dunnett's tests (Bonferroni correction), which compare treatment groups to a single control, were conducted on day 14 data to determine if the preference scores exhibited by the METH 0.3 and METH 0.56 groups differed from controls. These analyses are important to determine if treatment groups exhibited full or partial extinction. All analyzes were considered significant at $p<0.05$.

\section{RESULTS \\ LITTER PARAMETERS}

Data gathered from the PN and PS-exposed pups revealed no significant effect of prenatal treatment on the number of pups born, the ratio of male vs. female pups, righting reflex, negative geotaxis, or eye opening (data not shown). Further, there was no significant effect of Prenatal Treatment on dam weight gain (Figure 1A) or pup weight gain (Figure 1B). These findings indicate that PN exposure did not disrupt postnatal development according to the ontogenetic measures used in the present study.

\section{EXPERIMENT 1: METH SELF-ADMINISTRATION}

A $2 \times 2 \times 5$ mixed-factorial ANOVA revealed main effects of Dose $[F(1,34)=43.6, p<0.001]$ and Prenatal Treatment $[F(1$, $34)=4.3, p<0.05]$, and a significant Dose $\times$ Prenatal Treatment interaction $[F(1,34)=4.9, p<0.05]$. Sex was not a significant factor in the analyses. The METH self-administration data are presented as two separate dose-response curves in Figure 2. As can be seen in Figure 2, varying the unit dose of IV METH produced the standard " $U$ " shaped curve for the PN and PS groups, which is commonly observed when animals self-administer psychostimulant drugs, such as amphetamines or cocaine (Yokel, 1987). Furthermore, the PS and PN groups exhibited similar means of active lever presses when allowed to respond for the lowest and highest unit doses of IV METH tested. However, PS rats clearly showed peak responding at the $0.025-\mathrm{mg} / \mathrm{kg} /$ infusion dose, whereas the $\mathrm{PN}$ animals exhibited peak responding between the $0.005-$ and $0.025-\mathrm{mg} / \mathrm{kg} /$ infusion doses. The main effect of Prenatal Treatment indicates that PN animals responded more for METH compared to the PS rats. The significant Dose $\times$ Prenatal Treatment interaction indicates that the PN dose-response curve shifted to the left. Analysis of inactive lever responding revealed a significant effect of Dose $[F(1,34)=26.9, p<0.001]$ and no other significant effects were found. The means $( \pm \mathrm{SEM})$ for inactive lever responding were 10.0 ( \pm 1.6$), 8.9( \pm 1.3), 6.5( \pm 0.9), 5.0( \pm 0.8)$, and $3.9( \pm 0.6$; data not shown) for the $0.0005,0.0025,0.005,0.025$, and 1.0 doses, respectively. The main effect of dose shows that rats responded more on the inactive lever when the dose was 0.0005
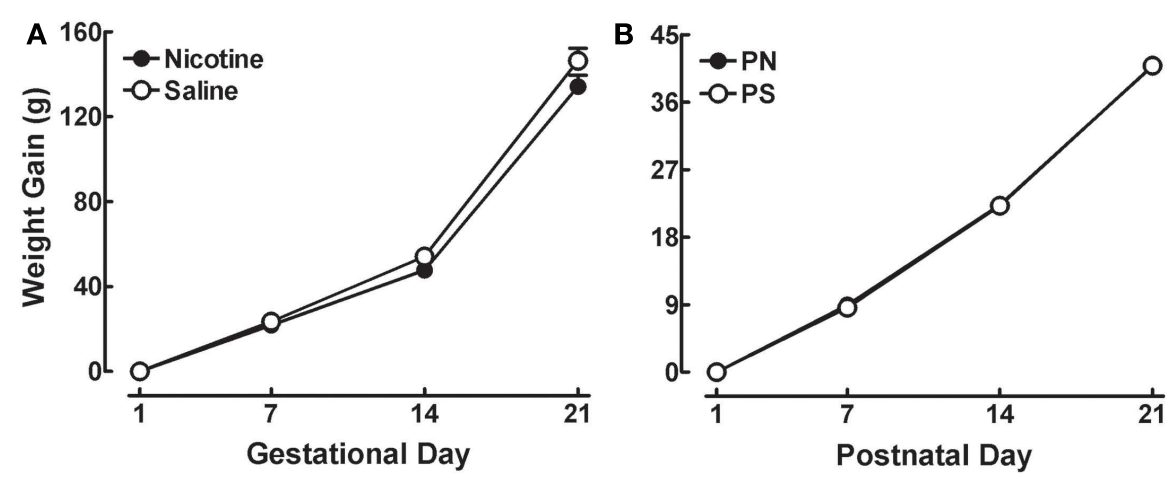

FIGURE 1 | (A) Mean ( \pm SEM) weight gain data for the Saline and Nicotine dams across gestation. (B) Mean ( \pm SEM) weight gain data for the PN and PS pups across PND 1-21. 
and responding on this lever decreased as the unit dose of METH increased.

These results indicate that the PN rats exhibited a leftward shift in the dose-response curve relative to rats in the PS treatment group. This indicates that $\mathrm{PN}$ rats were more sensitive to the reinforcing effects of IV METH compared to the PS animals.

\section{EXPERIMENT 2: METH-INDUCED CTA Acquisition of CTA}

A Sex $\times$ Prenatal Treatment $\times$ Dose $\times$ Day $(2 \times 2 \times 3 \times 3)$ mixedfactorial ANOVA was conducted on the weight-corrected data. The analysis revealed a main effect of Sex: $[F(1,224)=114.9$, $p<0.001]$, which indicates that females consumed more saccharin relative to males. According to this analysis females consumed an average of $0.06 \mathrm{ml} / \mathrm{g}$ of saccharin $(\mathrm{SEM}=0.001)$, whereas males consumed an average of $0.04 \mathrm{ml} / \mathrm{g}$ of saccharin $(\mathrm{SEM}=0.001$; data not shown). Percent of control values were calculated, and a Sex $\times$ Prenatal Treatment $\times$ Dose $\times$ Day $(2 \times 2 \times 2 \times 3)$ mixedfactorial ANOVA was conducted on these data in order to adequately assess potential sex differences in CTA. The analysis revealed no significant effects of Sex or Prenatal Treatment. Figure 3 shows the acquisition curves (\% of control) for PN and PS groups injected with METH 0.3 or $0.56 \mathrm{mg} / \mathrm{kg}$ by conditioning trials. The PN and PS groups represent both males and females; however, the factors of Prenatal Treatment are represented on Figure 3 because prenatal treatment was the focus of the experiment. The significant main effect of Day shows that animals treated with the METH US exhibited decreased saccharin consumption as a function of conditioning day $[F(2,152)=484.8$, $p<0.001]$ and the main effect of Dose indicates that overall the magnitude of CTA was greater in the METH $0.56 \mathrm{mg} / \mathrm{kg}$ group $[$ means $( \pm S E M)=0.667( \pm 0.018)]$, relative to the METH

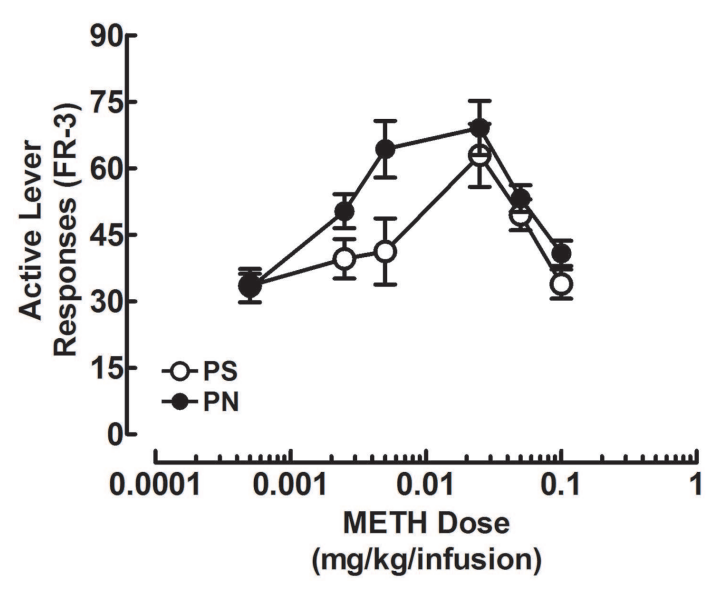

FIGURE 2 | Mean ( \pm SEM) active lever responses for the PS and PN groups are presented for the METH doses $0.0005,0.0025,0.005,0.025$, 0.05 , and $0.1 \mathrm{mg} / \mathbf{k g} /$ injection according to $\log _{10}$ scale. Data from the training dose, $0.05 \mathrm{mg} / \mathrm{kg} /$ injection, is shown on the graph as a point of reference, but was not included in the ANOVA. This point represents the average responding for $0.05 \mathrm{mg} / \mathrm{kg} /$ infusion METH from the day before testing with the $0.0005-$ to $0.1-\mathrm{mg} / \mathrm{kg} /$ infusion doses. PN animals showed a leftward shift of the dose-response curve relative to the PS rats [Prenatal Treatment $\times$ Dose interaction; $F(1,34)=4.9, p<0.05$ ].
$0.3 \mathrm{mg} / \mathrm{kg}$ group [0.798 $( \pm 0.018) ; F(1,76)=26.9, p<0.001]$. Moreover, repeated saccharin-METH pairings produced a progressive increase in the magnitude of CTA, and greater avoidance behavior was observed from animals injected with the higher dose of $\mathrm{METH}$, according to the significant Day $\times$ Dose interaction $[F(2,152)=20.5, p<0.001]$.

\section{Extinction of CTA}

A $2 \times 2 \times 3 \times 14$ mixed-factorial ANOVA was conducted on the extinction data. There were no significant main effects or interactions with the factors of Sex or Prenatal Treatment. Figure 4 shows the saccharin preference data for the PN and PS groups injected with SAL or METH 0.3 or $0.56 \mathrm{mg} / \mathrm{kg}$ US as a function of extinction trials. The PN and PS groups represent both males and females; however, the factors of Prenatal Treatment are represented on Figure 4 because prenatal treatment was the focus of the study. Scores above 0.5 indicate a preference for saccharin, whereas scores below 0.5 indicate a preference for water.

According to the significant main effect of Dose $[F(2$, $112)=103.8, p<0.001]$, different magnitudes of CTA were exhibited by animals treated with SAL, METH 0.3, and METH $0.56 \mathrm{mg} / \mathrm{kg}$. Thus, overall, rats treated with SAL or METH $0.3 \mathrm{mg} / \mathrm{kg}$ exhibited saccharin preference of $0.86( \pm 0.03)$ and 0.58 ( \pm 0.03$)$, respectively; whereas the METH $0.56 \mathrm{mg} / \mathrm{kg}$ group showed an overall water preference $0.29( \pm 0.03)$. The main effect of Day $[F(13,1456)=38.9, p<0.001]$ shows that preference scores changed following repeated, non-reinforced exposure to the saccharin/water test stimuli; and the Day $\times$ Dose interaction $[F(26,1456)=7.5, p<0.001]$ indicates that the preference scores changed across testing days and was dependent on whether the conditioning dose was 0.3 or $0.56 \mathrm{mg} / \mathrm{kg}$.

In order to assess responding following repeated, nonreinforced exposure to the CS, within-subjects comparisons

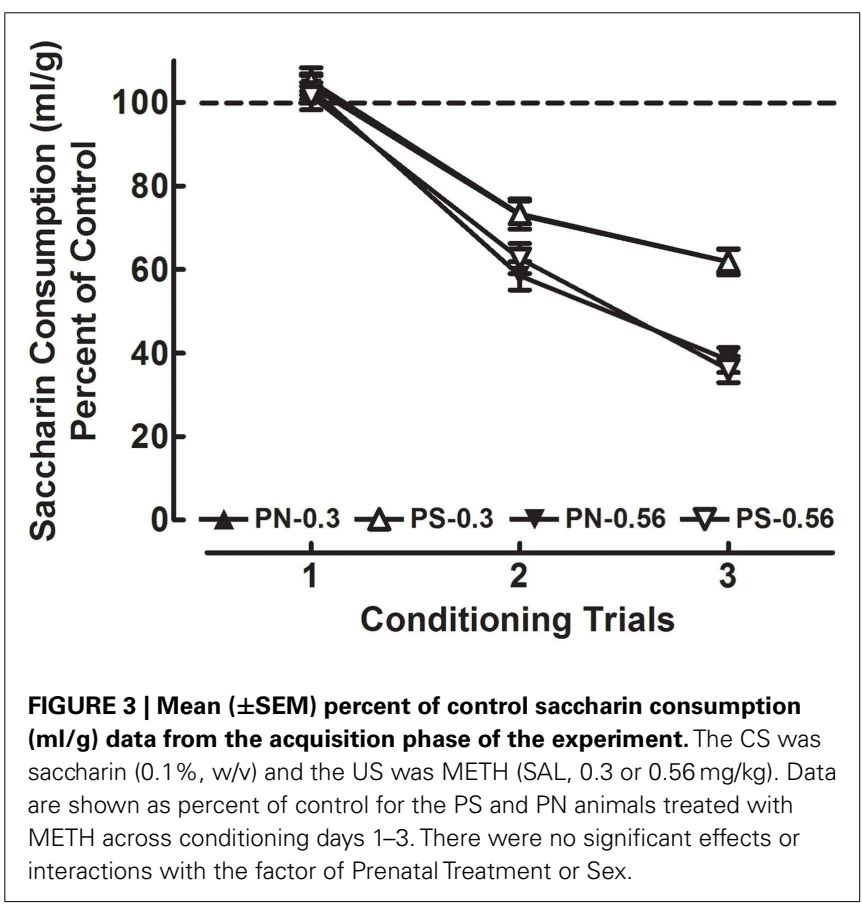




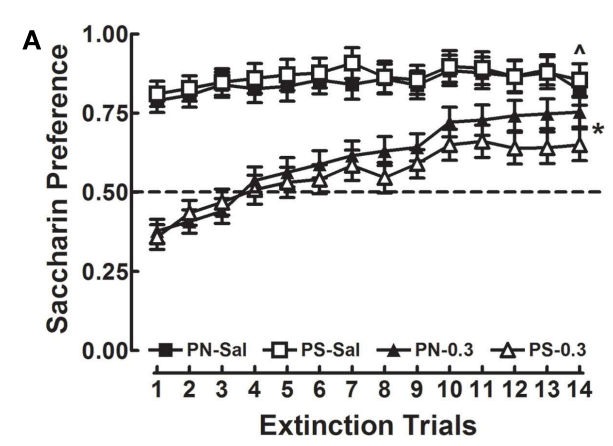

FIGURE 4 | Mean ( \pm SEM) preference scores for the 14 consecutive two-bottle extinction tests are presented for the PS and PN animals that were treated with either SAL or $0.3 \mathrm{mg} / \mathrm{kg}$ METH (A) or SAL or $\mathbf{0 . 5 6} \mathbf{~ m g} / \mathbf{k g}$ METH (B). Scores above 0.5 indicate a preference for saccharin and scores below 0.5 indicate a preference for water. There

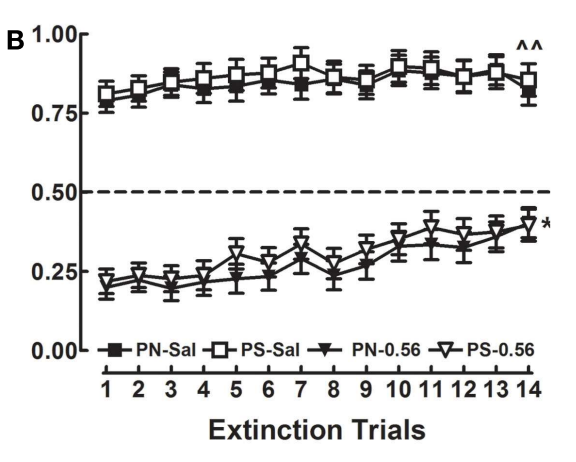

were no significant effects or interactions with the factor of Prenatal Treatment or Sex. Significant differences between days 1 and 14 are indicated by $*(p<0.001)$. Significant differences between SAL and the $0.3-$ and $0.56-\mathrm{mg} / \mathrm{kg} \mathrm{METH}$ groups are indicated by ${ }^{\wedge}(p<0.05)$ and ${ }^{\wedge}$ $(p<0.001)$. between day 1 and 14 were conducted for the SAL, METH 0.3, and METH 0.56 groups, as described by the Day $\times$ Dose interaction. Animals in the SAL group showed a consistent preference for saccharin between testing days 1 and $14[t(39)=1.49$, $p>0.05]$. Rats treated with METH 0.3 initially showed a preference for water on day 1 , and repeated exposure to the CS/water resulted in extinction, which is represented as a saccharin preference on day $14[t(41)=9.37, p<0.001]$. The change in responding represents a $91 \%$ increase in the preference score. Animals in the METH 0.56 group exhibited a preference for water on day 1 , and despite a similar $91 \%$ increase in preference score, these animals maintained an overall preference water on day 14 $[t(41)=4.62, p<0.001$; Figure 4]. Dunnette's tests were conducted for data from the three groups on day 14 to determine if either the METH 0.3 or 0.56 groups were different than controls on the final day of extinction training. The preference scores from both the METH 0.3 and 0.56 groups were significantly lower than the SAL group $(p<0.05$ and $p<0.001$, respectively). These findings show that non-reinforced presentation of the CS produced extinction of the CR for both doses of the METH US and 14 days of extinction did not fully extinguish the CR relative to the SAL controls. These data indicate that PN exposure did not result in differential acquisition or extinction of METHinduced CTA when rats were conditioned and tested during adulthood.

\section{DISCUSSION}

The present experiments determined if IV PN exposure altered the reinforcing and/or aversive effects of METH in adult offspring. In experiment 1, PS and PN rats were trained to self-administer METH according to a FR-3 schedule of reinforcement. Following stable responding, rats were tested on varying doses of METH and dose-response curves were generated for both groups. Although both the PN and PS treatment groups exhibited the standard "U"shaped dose-response curve (Yokel, 1987), PN rats exhibited more active lever responses for doses of METH, relative to controls. The leftward shift in the PN rats' dose-response curve, as indicated by a significant main effect of prenatal treatment and a prenatal treatment $\times$ dose interaction, indicates that these animals were more sensitive to the reinforcing effects of METH compared to rats in the PS group.

The enhanced sensitivity to IV METH exhibited by offspring in the present study may be related to nicotine's ability to induce transcriptional activation of genes associated with drug reward and sensitization of the mesocorticolimbic system (Zhu et al., 2007; Levine et al., 2011). In a study by Levine et al. (2011), mice were preexposed to oral nicotine or water and then were treated with either saline or cocaine. Nicotine-treated mice exhibited enhanced cocaine-induced locomotor sensitization and cocainemediated conditioned place preference, and increased cocaineinduced expression of accumbal FosB relative to controls that did not receive nicotine treatment. The nicotine-mediated increase in cocaine-induced FosB expression was associated with changes in histone acetylation, suggesting an epigenetic explanation of the findings (Levine et al., 2011). These and other findings suggest that PN may modulate histone acetylation of FosB during neurodevelopment, potentially leading to alterations in other transcription factors, and $\mathrm{D}_{1}$ mediated signaling proteins (Teegarden et al., 2008). Indeed, previous research demonstrates that PN alters MAPk and PI3k signaling pathways (Wei et al., 2011) and increases levels of mRNA and protein of brain-derived neurotrophic factor throughout the mesocorticolimbic DA system (Harrod et al., 2011; Wei et al., 2011). Thus, determining the effects of IV PN on histone acetylation at FosB expression in offspring is of interest for future investigation.

Adolescent offspring of continuous PN exposure were previously reported to exhibit altered responding for IV cocaine. In that study Franke et al. (2008) investigated cocaine selfadministration using two different concentrations of the reinforcer, 200 or $500 \mu \mathrm{g} / \mathrm{kg} /$ infusion, and focused on the acquisition of FR-1 responding using adolescent offspring. These findings are important because they demonstrate that rats treated with continuous $\mathrm{PN}$ acquired self-administration at different concentrations of cocaine: PN-treated rats acquired stable responding when the concentration was 500 , but not $200 \mu \mathrm{g} / \mathrm{kg} /$ infusion, whereas the opposite relationship was observed for controls. Thus, these data show that PN rats required a concentration of cocaine that was 2.5 times higher than the dose needed for controls to acquire the 
response. Thus, the Franke et al. (2008) experiment suggests that during the developmental period of adolescence, the PN animals were less sensitive to the stimulus properties of IV cocaine than PS offspring.

The present experiment focused on changes in the relative sensitivity to IV METH after adult offspring acquired stable responding on a FR-3 schedule of reinforcement. Thus, offspring were tested intermittently with various novel doses of the reinforcer after maintenance of the CR was demonstrated. That adult PN rats self-administered a lower dose of METH relative to controls demonstrates that $\mathrm{PN}$ exposure alters the stimulus properties of IV METH. Moreover, these effects of IV PN exposure appear to endure, as offspring did not receive exposure to any drug between birth and METH self-administration, which began during adulthood. This is an important point because nicotine exposure during adulthood can alter gene expression and this can lead to an altered response to other drugs of abuse, such as cocaine (Levine et al., 2011). Further experiments need to determine if PS and $\mathrm{PN}$ animals show differences in METH self-administration when progressive-ratio schedules of reinforcement are used (Richardson and Roberts, 1996). Such data will be necessary to determine if IV $\mathrm{PN}$ exposure results in motivational differences for the reinforcing effects of METH. Moreover, these findings suggest that PN exposure may alter the function of various molecular targets for $\mathrm{METH}$, such as VMAT and DAT, through which this drug changes synaptic monoamine levels (Dwoskin and Crooks, 2002). Overall, PN exposure alters the appetitive stimulus properties of psychostimulant drugs like cocaine, nicotine, and METH, and these findings suggest that such alterations in the reinforcing effects of abused drugs could be one factor that underlies the increased vulnerability to drug abuse that is documented in offspring of in utero tobacco smoke exposure.

The aversive effects of abused drugs may play an important role in offsetting the transition from recreational drug use to chronic drug taking behavior (see Davis and Riley, 2010). Preclinical research shows that nicotine exposure during early stages of development (e.g., periadolescence) can alter learning about the aversive effects of abused drugs in adulthood (Rinker et al., 2011). Therefore it was also of interest to determine if PN exposure affects the acquisition and expression of METH-induced CTA. Experiment 2 showed that PN exposure did not alter METH-induced CTA. PN and PS animals acquired CTA in a dose-dependent manner and both treatment groups exhibited similar magnitudes of conditioned responding, as measured by the acquisition and extinction procedures. Thus, $\mathrm{PN}$ exposure did not alter the aversive effects of METH when measured by the CTA procedure. Further research needs to determine if a higher dose of IV PN will impact the acquisition and expression of METH-induced CTA in offspring in order to fully determine if in utero nicotine exposure can alter learning about the aversive effects of METH.

Low birth weight in offspring of maternal smoking is well documented (Ernst et al., 2001). These effects are produced, in part, from nicotine, because PN exposure alone produces lower birth weights in exposed rodent offspring relative to controls. This effect has been observed in animal models using the continuous, IV, and drinking water methods of nicotine exposure (e.g., Slotkin, 2004; LeSage et al., 2006; Levin et al., 2006; Schneider et al., 2010), and in general, the differences in weight are resolved with maturity. Lowering the dose of $\mathrm{PN}$ avoids birth weight deficits in offspring across all of the abovementioned exposure models (e.g., Franke et al., 2008; Schneider et al., 2010; Harrod et al., 2011), yet these studies report neurochemical and behavioral alterations in the offspring. The low dose, IV model of PN administration used in the present experiment has not produced altered birth weight or weight gain in offspring (Harrod et al., 2011; Lacy et al., 2011, 2012), according to the described procedures. The current findings add to a growing literature, which shows that PN exposure produces neurochemical and behavioral changes in offspring born of normal birth weight (Pauly et al., 2004; Franke et al., 2007, 2008; Schneider et al., 2010).

Taken together, the present findings indicate that IV PN exposure altered the stimulus properties of METH when an appetitive conditioning procedure was used. This finding adds to a growing literature, which shows that IV PN can alter the behavior of offspring in later stages of development (LeSage et al., 2006; Harrod et al., 2011; Lacy et al., 2011). An advantage to using the IV route of administration is that IV injection allows for $100 \%$ bioavailability of nicotine absorption and near instantaneous distribution. And, as previously mentioned, the IV route of administration closely mimics the pharmacokinetics of nicotine produced through cigarette smoke inhalation. Another advantage is that this exposure method may be used to deliver less daily amounts of nicotine relative to other exposure models (Russell and Feyerabend, 1978; Mactutus, 1989; Booze et al., 1999; Benowitz et al., 2009). Lacy et al. (2011) showed that the IV exposure method used in the present study produced deficits in prepulse inhibition of the acoustic starthe response that are consistent with that induced by a continuous GN exposure model (i.e., Popke et al., 1997), for example. There are clearly disadvantages to all methods of PN exposure. A disadvantage of the present model may be that it requires direct interaction with the dam in order to administer the daily prenatal injections. On the other hand, this method affords a unique opportunity to monitor the animals' progression through pregnancy without adding what would otherwise be considered additional stress. Another disadvantage is that the present model uses nicotine to mimic maternal smoking when there are approximately 4,000 active compounds in cigarette smoke.

The present experiments indicate that offspring of IV PN exposure showed increased sensitivity to the reinforcing effects of the highly abused drug METH. This finding suggests that women who smoke a "low" number of daily cigarette during pregnancy may alter the development of motivational systems in their offspring. Increased sensitivity to the reinforcing properties of abused drugs may be one important factor that mediates the increased vulnerability toward substance abuse in the offspring of women who smoke tobacco throughout pregnancy.

\section{ACKNOWLEDGMENTS}

The authors thank Lauren Ballina, Rachel Singleton, and Bonnie Barte for their technical expertise on this study. We also would like to acknowledge Rick Bevins, Ph.D. and Nichole Neugebauer, Ph.D. for their expert consultation on the operant experiments. This research was supported by a Research Productivity Scholar grant from the University of South Carolina (KA-21) and a grant from the National Institute for Drug Abuse (DA 021287). 


\section{REFERENCES}

Benowitz, N. L., Hukkanen, J., and Jacob, P. III. (2009). Nicotine chemistry, metabolism, kinetics and biomarkers. Handb. Exp. Pharmacol. 192, 29-60.

Booze, R. M., Welch, M. A., Wood, M. L., Billings, K. A., Apple, S. R., and Mactutus, C. F. (1999). Behavioral sensitization following repeated intravenous nicotine administration: gender differences and gonadal hormones. Pharmacol. Biochem. Behav. 64, 827-839.

Brennan, P. A., Grekin, E. R., Mortensen, E. L., and Mednick, S. A. (2002). Relationship of maternal smoking during pregnancy with criminal arrest and hospitalization for substance abuse in male and female adult offspring. Am. J. Psychiatry 159, 48-54.

Buka, S. L., Shenassa, E. D., and Niaura, R. (2003). Elevated risk of tobacco dependence among offspring of mothers who smoked during pregnancy: a 30-year prospective study. Am. J. Psychiatry 160, 1978-1984.

Castles, A., Adams, E. K., Melvin, C. L., Kelsch, C., and Boulton, M. L. (1999). Effects of smoking during pregnancy. Five meta-analyses. Am. J. Prev. Med. 16, 208-215.

Cornelius, M. D., and Day, N. L. (2009). Developmental consequences of prenatal tobacco exposure. Curr. Opin. Neurol. 22, 121-125.

Davis, C. M., and Riley, A. L. (2010). Conditioned taste aversion learning: implications for animal models of drug abuse. Ann. N. Y. Acad. Sci. 1187, 247-275.

Dwoskin, L. P., and Crooks, P. A. (2002). A novel mechanism of action and potential use for lobeline as a treatment for psychostimulant abuse. Biochem. Pharmacol. 63, 89-98.

Dwyer, J. B., Broide, R. S., and Leslie, F. M. (2008). Nicotine and brain development. Birth Defects Res. C Embryo Today 84, 30-44.

Dwyer, J. B., McQuown, S. C., and Leslie, F. M. (2009). The dynamic effects of nicotine on the developing brain. Pharmacol. Ther. 122, 125-139.

Ernst, M., Moolchan, E. T., and Robinson, M. L. (2001). Behavioral and neural consequences of prenatal exposure to nicotine. J. Am. Acad. Child Adolesc. Psychiatry 40, 630-641.

Franke, R. M., Belluzzi, J. D., and Leslie, F. M. (2007). Gestational exposure to nicotine and monoamine oxidase inhibitors influences cocaineinduced locomotion in adolescent rats. Psychopharmacology (Berl.) 195, 117-124.
Franke, R. M., Park, M., Belluzzi, J. D., and Leslie, F. M. (2008). Prenatal nicotine exposure changes natural and drug-induced reinforcement in adolescent male rats. Eur. J. Neurosci. 27, 2952-2961.

Gether, U., Andersen, P. H., Larsson, O. M., and Schousboe, A. (2006). Neurotransmitter transporters: molecular function of important drug targets. Trends Pharmacol. Sci. 27, 375-383.

Harrod, S. B., Dwoskin, L. P., Crooks, P. A., Klebaur, J. E., and Bardo, M. T. (2001). Lobeline attenuates d-methamphetamine self-administration in rats. J. Pharmacol. Exp. Ther. 298, 172-179.

Harrod, S. B., Lacy, R. T., Zhu, J., Hughes, B. A., Perna, M. K., and Brown, R. W. (2011). Gestational IV nicotine produces elevated brain-derived neurotrophic factor in the mesocorticolimbic dopamine system of adolescent rat offspring. Synapse 65, 1382-1392.

Heath, C. J., and Picciotto, M. R. (2009). Nicotine-induced plasticity during development: modulation of the cholinergic system and long-term consequences for circuits involved in attention and sensory processing. Neuropharmacology 56(Suppl. 1), 254-262.

Holson, R. R., and Pearce, B. (1992). Principles and pitfalls in the analysis of prenatal treatment effects in multiparous species. Neurotoxicol. Teratol. 14, 221-228.

Kandel, D. B., Wu, P., and Davies, M. (1994). Maternal smoking during pregnancy and smoking by adolescent daughters. Am. J. Public Health 84, 1407-1413.

Kane, V. B., Fu, Y., Matta, S. G., and Sharp, B. M. (2004). Gestational nicotine exposure attenuates nicotine-stimulated dopamine release in the nucleus accumbens shell of adolescent Lewis rats. J. Pharmacol. Exp. Ther. 308, 521-528.

Lacy, R. T., Hord, L. L., Morgan, A. J., and Harrod, S. B. (2012). Intravenous gestational nicotine exposure results in increased motivation for sucrose reward in adult rat offspring. Drug Alcohol Depend. doi: 10.1016/j.drugalcdep.2012.01.025. [Epub ahead of print].

Lacy, R. T., Mactutus, C. F., and Harrod, S. B. (2011). Prenatal IV nicotine exposure produces a sex difference in sensorimotor gating of the auditory startle reflex in adult rats. Int. J. Dev. Neurosci. 29, 153-161.

Laviolette, S. R., and van der Kooy, D. (2004). The neurobiology of nicotine addiction: bridging the gap from molecules to behaviour. Nat. Rev. Neurosci. 5, 55-65.

LeSage, M. G., Gustaf, E., Dufek, M. B., and Pentel, P. R. (2006). Effects of maternal intravenous nicotine administration on locomotor behavior in pre-weanling rats. Pharmacol. Biochem. Behav. 85, 575-583.

Levin, E. D., Lawrence, S., Petro, A., Horton, K., Seidler, F. J., and Slotkin, T. A. (2006). Increased nicotine selfadministration following prenatal exposure in female rats. Pharmacol. Biochem. Behav. 85, 669-674.

Levin, E. D., Wilkerson, A., Jones, J. P., Christopher, N. C., and Briggs, S. J. (1996). Prenatal nicotine effects on memory in rats: pharmacological and behavioral challenges. Brain Res. Dev. Brain Res. 97, 207-215

Levine, A., Huang, Y., Drisaldi, B., Griffin, E. A. Jr., Pollak, D. D., Xu, S., Yin, D., Schaffran, C., Kandel, D. B., and Kandel, E. R. (2011). Molecular mechanism for a gateway drug: epigenetic changes initiated by nicotine prime gene expression by cocaine. Sci. Transl. Med. 3, 107ra109.

Mactutus, C. F. (1989). Developmental neurotoxicity of nicotine, carbon monoxide, and other tobacco smoke constituents. Ann. N. Y. Acad. Sci. 562, 105-122.

Mactutus, C. F., Herman, A. S., and Booze, R. M. (1994). Chronic intravenous model for studies of drug (Ab) use in the pregnant and/or group-housed rat: an initial study with cocaine. Neurotoxicol. Teratol. 16, 183-191.

Park, M. K., Loughlin, S. E., and Leslie, F. M. (2006). Gestational nicotine-induced changes in adolescent neuronal activity. Brain Res. 1094, 119-126.

Pauly, J. R., Sparks, J. A., Hauser, K. F., and Pauly, T. H. (2004). In utero nicotine exposure causes persistent, gender-dependant changes in locomotor activity and sensitivity to nicotine in C57Bl/6 mice. Int. J. Dev. Neurosci. 22, 329-337.

Paz, R., Barsness, B., Martenson, T., Tanner, D., and Allan, A. M. (2007). Behavioral teratogenicity induced by nonforced maternal nicotine consumption. Neuropsychopharmacology 32, 693-699.

Popke, E. J., Tizabi, Y., Rahman, M. A., Nespor, S. M., and Grunberg, N. E. (1997). Prenatal exposure to nicotine: effects on prepulse inhibition and central nicotinic receptors. Pharmacol. Biochem. Behav. 58, 843-849.

Reichel, C. M., Linkugel, J. D., and Bevins, R. A. (2008). Bupropion differentially impacts acquisition of methamphetamine self-administration and sucrosemaintained behavior. Pharmacol. Biochem. Behav. 89, 463-472.

Richardson, N. R., and Roberts, D. C. (1996). Progressive ratio schedules in drug self-administration studies in rats: a method to evaluate reinforcing efficacy. J. Neurosci. Methods 66, 1-11.

Richardson, S. A., and Tizabi, Y. (1994). Hyperactivity in the offspring of nicotine-treated rats: role of the mesolimbic and nigrostriatal dopaminergic pathways. Pharmacol. Biochem. Behav. 47, 331-337.

Rinker, J. A., Hutchison, M. A., Chen, S. A., Thorsell, A., Heilig, M., and Riley, A. L. (2011). Exposure to nicotine during periadolescence or early adulthood alters aversive and physiological effects induced by ethanol. Pharmacol. Biochem. Behav. 99, 7-16.

Russell, M. A., and Feyerabend, C. (1978). Cigarette smoking: a dependence on high-nicotine boli. Drug Metab. Rev. 8, 29-57.

Schneider, T., Bizarro, L., Asherson, P. J., and Stolerman, I. P (2010). Gestational exposure to nicotine in drinking water: teratogenic effects and methodological issues. Behav. Pharmacol. 21, 206-216.

Slotkin, T. A. (2004). Cholinergic systems in brain development and disruption by neurotoxicants: nicotine, environmental tobacco smoke, organophosphates. Toxicol. Appl. Pharmacol. 198, 132-151.

Slotkin, T. A., Orband-Miller, L., Queen, K. L., Whitmore, W. L., and Seidler, F. J. (1987). Effects of prenatal nicotine exposure on biochemical development of rat brain regions: maternal drug infusions via osmotic minipumps. J. Pharmacol. Exp. Ther. 240, 602-611.

Sulzer, D., Sonders, M. S., Poulsen, N. W., and Galli, A. (2005). Mechanisms of neurotransmitter release by amphetamines: a review. Prog. Neurobiol. 75, 406-433.

Teegarden, S. L., Nestler, E. J., and Bale, T. L. (2008). Delta FosBmediated alterations in dopamine signaling are normalized by a palatable high-fat diet. Biol. Psychiatry 64, 941-950.

Vorhees, C. V. (1986). "Principles of behavioral teratology," in Handbook of Behavioral Teratology, eds E. P. Riley and C. V. Vorhees (New York, NY: Plenum Press), 23-48.

Wei, J., Wang, J., Dwyer, J. B., Mangold, J., Cao, J., Leslie, F. M., and Li, M. D. 
(2011). Gestational nicotine treatment modulates cell death/survivalrelated pathways in the brains of adolescent female rats. Int. J. Neuropsychopharmacol. 14, 91-106.

Weissman, M. M., Warner, V., Wickramaratne, P. J., and Kandel, D. B. (1999). Maternal smoking during pregnancy and psychopathology in offspring followed to adulthood. J. Am. Acad. Child Adolesc. Psychiatry 38, 892-899.

Winzer-Serhan, U. H. (2008). Longterm consequences of maternal smoking and developmental chronic nicotine exposure. Front. Biosci. 13, 636-649.
Yokel, R. A. (1987). "Intravenous selfadministration: response rates, the effects of pharmacological challenges, and drug preference," in Methods of Assessing the Reinforcing Properties of Abused Drugs, ed. M. A. Bozarth (New York: SpringerVerlag), 1-33.

Zhu, H., Lee, M., Agatsuma, S., and Hiroi, N. (2007). Pleiotropic impact of constitutive fosB inactivation on nicotine-induced behavioral alterations and stress-related traits in mice. Hum. Mol. Genet. 16, 820-836.

Zhu, J., Takita, M., Konishi, Y., Sudo, M., and Muramatsu, I. (1996). Chronic nicotine treatment delays the developmental increase in brain muscarinic receptors in rat neonate. Brain Res. 732, 257-260.

Conflict of Interest Statement: The authors declare that the research was conducted in the absence of any commercial or financial relationships that could be construed as a potential conflict of interest.

Received: 18 January 2012; paperpending published: 20 February 2012; accepted: 30 May 2012; published online: 18 June 2012.
Citation: Harrod SB, Lacy RT and Morgan AJ (2012) Offspring of prenatal IV nicotine exposure exhibit increased sensitivity to the reinforcing effects of methamphetamine. Front. Pharmacol. 3:116. doi: 10.3389/fphar.2012.00116

This article was submitted to Frontiers in Neuropharmacology, a specialty of Frontiers in Pharmacology.

Copyright (c) 2012 Harrod, Lacy and Morgan. This is an open-access article distributed under the terms of the Creative Commons Attribution Non Commercial License, which permits noncommercial use, distribution, and reproduction in other forums, provided the original authors and source are credited. 